Check for updates

Cite this: RSC Adv., 2017, 7, 19145

\title{
Electrofluid enhanced hydrolysis of maize starch and its impacts on physical properties
}

\author{
Yuyi Zhou, ${ }^{\text {ab }}$ Yamei Jin, ${ }^{\text {ab }}$ Na Yang, (D)*ab Zhengjun Xie ${ }^{\text {abc }}$ and Xueming Xu*abc
}

To achieve high-output, successional, and efficient hydrolysis of carbohydrate polymers is an increasing concern in the food and chemical industries. Existing electric field techniques are limited by the occurrence of electrochemical reactions in the electroconductive medium during alternative current (AC) and direct current (DC) treatment. The electrofluid technique outperforms conventional hydrolysis of starch under mild conditions. The said technique was applied to maize starch hydrolysis to confirm its feasibility and effectiveness. The induced-electric-field-assisted hydrolysis (IEFAH) of maize starch improved the reducing sugar content by $175.05 \%, 132.43 \%$, and $89.62 \%$, respectively, when compared to static immersion, conventional heating hydrolysis $(\mathrm{CHH})$, and continuous-flow heating hydrolysis $(\mathrm{CFHH})$ after $120 \mathrm{~h}$. Increase in excitation voltage and reactor series both significantly increased the yield. Sugar content increased by $59.88 \%$ at $30{ }^{\circ} \mathrm{C}$ and by $118.99 \%$ at $40{ }^{\circ} \mathrm{C}$ after $60 \mathrm{~h}$ compared to the control $(0 \mathrm{~V})$. The favorable effect on maize starch hydrolysis may be attributable to the electric field damaging the starch granule surfaces and crystalline structure, as confirmed by SEM, XRD, and DSC analyses. To this effect, the electrofluid technique using induced electric fields (IEF) is promising in terms of efficient starch hydrolysis without side reactions owing to the avoidance of rigorous heating, heavy metal leakage, and sample contamination.

Received 3rd January 2017

Accepted 20th March 2017

DOI: $10.1039 / \mathrm{c} 7 \mathrm{ra00080d}$

rsc.li/rsc-advances sugar is often necessary to accelerate product formation and improve volumetric efficiency. ${ }^{6}$

There are two main approaches to transforming starches into small-molecule chemicals: enzymatic hydrolysis and acidic hydrolysis. Acidic hydrolysis is challenging because it is difficult to disrupt the recalcitrant crystalline structure of starch under mild conditions. In a previous study, after four days of the hydrothermal transformation of starch into monosaccharide solution at $2.2 \mathrm{M} \mathrm{HCl}$ and $35{ }^{\circ} \mathrm{C}$, only $59 \%$ of the starch was solubilized; after 15 days, almost all (98\%) of the starch granules were dissolved. ${ }^{7}$ This is due to the fact that the presence of numerous hydrogen bonds between chemical chains, the starch is structurally stable. ${ }^{8}$ Hydrothermal liquefaction technology, which involves the hydrothermal decomposition of various carbohydrates in aqueous solutions at $180{ }^{\circ} \mathrm{C}$, is affordable, as well as eco-friendly as it does not necessitate organic solvents, catalysts, or surfactants. Though the recalcitrant crystalline structure can be destroyed under harsh conditions, unexpected glucose side reactions also occur during the hydrolysis. ${ }^{9}$ Enzymatic hydrolysis, on the other hand, shows limited activity, and necessitates expensive enzyme material. ${ }^{10}$

Researchers have developed a number of innovative techniques for effectively hydrolyzing starch into monosaccharides and modified substances including ultrasonic treatment, ${ }^{11}$ high pressure processing, ${ }^{12}$ and microwave irradiation, ${ }^{13}$ which are promising in regards to rate enhancement, reaction time reduction, yield improvement, and the elimination of byproducts. A high-
${ }^{a}$ State Key Laboratory of Food Science and Technology, Jiangnan University, Wuxi 214122, China. E-mail: yangna@jiangnan.edu.cn; xmxu@jiangnna.edu.cn; Fax: +86 510 85919182; Tel: +86 51085919182

${ }^{b}$ School of Food Science and Technology, Jiangnan University, Wuxi 214122, China 'Synergetic Innovation Center of Food Safety and Nutrition, Jiangnan University, Wuxi 214122, China 
intensify pulsed electric field has also been used to modify starch physical properties with various crystal types; it requires only a brief treatment time, as well, owing to its high power input and high voltage electrical discharges. ${ }^{13}$ However, the hydrolysis, degradation, and modification of starch induces adverse electrochemical reactions that occur when metal electrodes are inserted into electroconductive media, resulting in electrode surface corrosion, heavy metal contamination during AC and DC treatment. ${ }^{14,15}$ Thus, the large scale application of existing electrotechnologies in the starch industry remains limited.

When an electrolyte solution is used as the secondary coil, the excitation voltage applied to the primary coil induces an alternating electric field in the media without necessitating metal electrodes. ${ }^{\mathbf{1 6}, \mathbf{1 7}}$ In addition, under the IEF, the orientational electromigration of charge-carrying solutes can accelerate mass transport. ${ }^{18}$ Fluidic reactors have garnered a great deal of attention in recent decades because of their advantages over traditional batch reactors, including accelerated heat- and mass-transfer, operational safety, precise control of reaction time, and ease of scale-up. ${ }^{19,20}$ Therefore, electrofluid technique combined the IEF with fluidic reactors facilitates starch hydrolysis throughout long-term treatment, thus avoiding the problems mentioned above.

There has been no previous report on maize starch hydrolysis in this field due to lacking technical means. In this study, we explored the IEFAH in effort to establish an alternative processing method and to investigate the induced electric field (magnetoelectric coupling) effect on maize starch under mild conditions. $\mathrm{CFHH}, \mathrm{CHH}$, and static immersion without IEF were used as controls. The effects of temperature, excitation voltage, and reactor series (put reactors in series in the system) on the reducing sugar content were explored, and several physical properties of maize starch after IEFAH treatment were investigated accordingly. The results presented below may provide useful information regarding electrofluid techniques for the efficient hydrolysis of carbohydrate polymer under mild conditions.

\section{Materials and methods}

\section{Experimental system}

This system is comprised of (1) power source (PS-6101, Taiwan Pusi Instruments Ltd. China); (2) fluidic reactor; (3) circulating water bath; (4) peristaltic pump; (5) water bath coupled with a magnetic force stirrer; (6) collection tank; (7) reaction channel; (8) cooling water channel; (9) cooling water chamber; (10) glass spiral tube; (11) silicone steel core; and (12) primary coil (Fig. 1a and $b$ ). The mixtures of powder samples and acidic solvents were placed in the collection tank and then driven by the peristaltic pump to circulate in the system, acting as a secondary coil (a glass spiral tube as the supporting tube, $N_{\mathrm{S} i}=23$, for $i=$ 1-4). The system can be constructed by flexibly increasing the number of the reactors in series connection. Compared to other batch and fluidic reactors, this system is also conducive to expansion for mass-production according to relevant products and process scales.

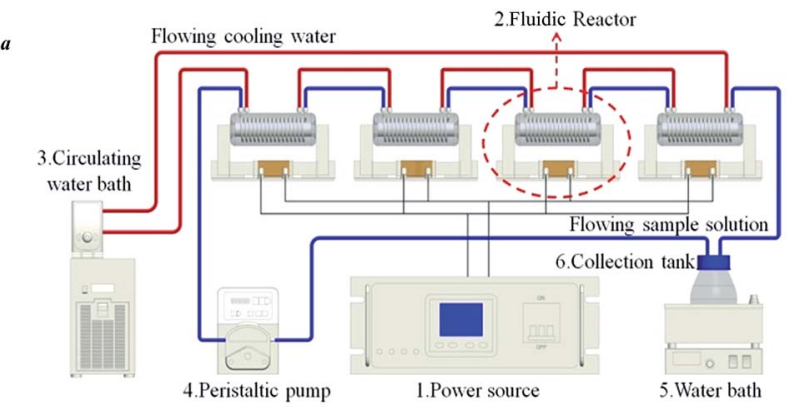

$b$

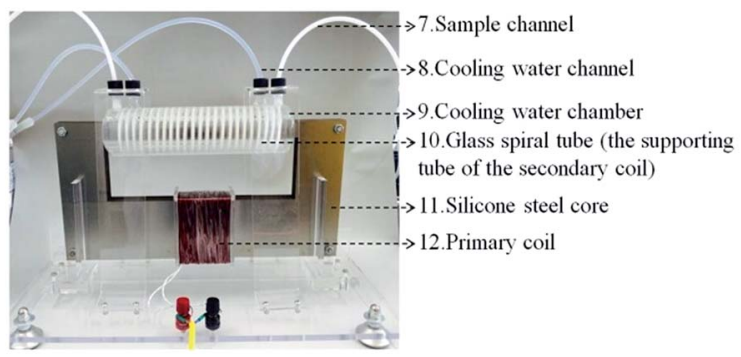

Fig. 1 Schematic diagram of the electrofluid system: (a) layout of instrumental chain; (b) fluidic reactor.

The series connection of the reactors is shown in Fig. 1a. The outlet of the flowing sample solution (FSS) on one reactor is linked to the inlet of the FSS in the next reactor, creating a closed-loop system. Each reactor is also equipped with a cooling water chamber, so the circulating water bath can maintain the temperature of the system.

The system operation was regulated by an excitation voltage ( $U_{\mathrm{P} i}$, for $\left.i=1-4\right)$ of $400 \mathrm{~Hz}\left(f_{i}\right.$, for $\left.i=1-4\right)$ applied on each primary coil $\left(N_{\mathrm{P} i}=92\right.$, for $\left.i=1-4\right)$ twining along the corresponding silicone steel core, while an alternating magnetic flux appeared in each silicone steel core. Then, an voltage $\left(E_{\mathrm{S} i}\right.$, for $i$

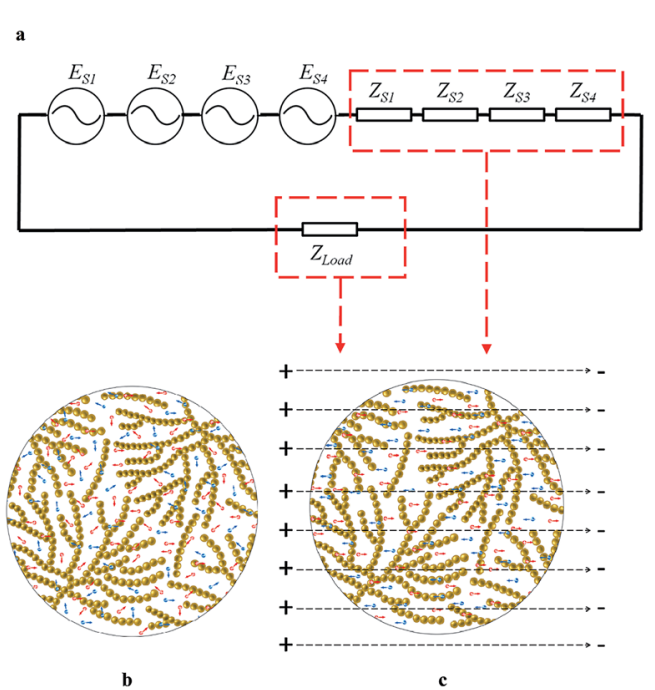

Fig. 2 The principle of the IEFAH treatment: (a) the equivalent circuit of the system; (b) Brown movement of free ions in starch hydrolysate; (c) the movement of free ions aligned with an electric field in starch hydrolysate. 
= 1-4) induced in each reactor and facilitated the FSS processing based on electromagnetic coupling effect. The equivalent circuits of the 4 -series connection reactors are shown in Fig. 2a.

Each reactor of the system is linked to a power source, so each primary coil is exposed to the same level of excitation voltage and frequency. The equations of the 4-series system describing operating parameters are as follows (eqn (1)-(7))::12

$$
\begin{gathered}
U_{\mathrm{P} i}=U_{\mathrm{P} 1}, U_{\mathrm{P} 2}, U_{\mathrm{P} 3}, \text { or } U_{\mathrm{P} 4} \\
f_{i}=f_{1}, f_{2}, f_{3}, \text { or } f_{4} \\
E_{\mathrm{P} i}=E_{\mathrm{S} 1}, E_{\mathrm{S} 2}, E_{\mathrm{S} 3} \text {, or } E_{\mathrm{S} 4} \\
N_{\mathrm{P} i}=N_{\mathrm{P} 1}, N_{\mathrm{P} 2}, N_{\mathrm{P} 3} \text {, or } N_{\mathrm{P} 4} \\
N_{\mathrm{S} i}=N_{\mathrm{S} 1}, N_{\mathrm{S} 2}, N_{\mathrm{S} 3} \text { or } N_{\mathrm{S} 4} \\
E_{\text {total }}=4 E_{\mathrm{S} 1}, 4 E_{\mathrm{S} 2}, 4 E_{\mathrm{S} 3} \text { or } 4 E_{\mathrm{S} 4} \\
Z_{\text {total }}=4 Z_{\mathrm{S} 1}, 4 Z_{\mathrm{S} 2}, 4 Z_{\mathrm{S} 3}, \text { or } 4 Z_{\mathrm{S} 4}
\end{gathered}
$$

where $Z_{\mathrm{S} 1}, Z_{\mathrm{S} 2}, Z_{\mathrm{S} 3}, Z_{\mathrm{S} 4}$ and $E_{\mathrm{S} 1}, E_{\mathrm{S} 2}, E_{\mathrm{S} 3}, E_{\mathrm{S} 4}$ are the equivalent internal impedance and induced voltage of each reactor, respectively. $E_{\text {total }}$ is the total induced voltage in 4 -series system. $Z_{\text {load }}$ and $Z_{\text {total }}$ are the impedance of the sample solution in the collection tank and FSS in all secondary coils respectively.

The sample solution in the collection tank $\left(Z_{\text {load }}\right)$ and all secondary coils $\left(Z_{\text {total }}\right)$ were exposed to an $E_{\text {total }}$ (Fig. 2a) so that the media (maize starch and dilute acid) served as the secondary coil and secondary circuit load under the IEF. Fig. $2 \mathrm{~b}$ and c depict the irregular movement of free ions like $\mathrm{H}^{+}$and $\mathrm{Cl}^{-}$ and their random collision on amylose and amylopectin owing to Brown motion, as well as their directional electromigration and more effective collision caused by electrodynamic force. The hydrolysis was actually intensified under mild conditions because the electrical effect surpassed the thermal effect.

\section{Procedure}

Maize starch (food grade, $13 \%$ moisture, $28 \%$ amylose, $72 \%$ amylopectin, $0.34 \%$ protein, $0.8 \%$ lipid, $0.09 \%$ ash; Minlong Food Co., Ltd., Wuxi, China) was kindly provided by Ingredion Co., Ltd., Shanghai, China. Forty grams of the starch sample was added to $0.15 \mathrm{~mol} \mathrm{~L}^{-1} \mathrm{HCl}$ (no. 10011018, Sinopharm Chemical Reagent Co., Ltd., Shanghai, China) at room temperature to form a native maize starch suspension $(8 \%, \mathrm{w} / \mathrm{v})$. For static immersion, the suspension was placed in a $50{ }^{\circ} \mathrm{C}$ water bath without stirring. For $\mathrm{CHH}$, the suspension was continuously stirred at $50^{\circ} \mathrm{C}$ and $100 \mathrm{rpm}$ via a blender (RW20 digital, IKA, Germany). For IEFAH, the suspension was circulated into the system at $350 \mathrm{~mL} \mathrm{~min}{ }^{-1}$ and $50{ }^{\circ} \mathrm{C}$ for continuousflow hydrolysis under excitation voltage at 50,100, and $150 \mathrm{~V}$; frequency at $400 \mathrm{~Hz}$; and temperature at 30,40 , and $50{ }^{\circ} \mathrm{C}$. Several treatments at the same conditions but without excitation voltage $(0 \mathrm{~V})$ were run as controls $(\mathrm{CFHH})$. The treatment period was 60 or $120 \mathrm{~h}$, and the hydrolysate $(\sim 4 \mathrm{~mL})$ was sampled at a certain interval for reducing sugar analysis.
Another one ( $\sim 4 \mathrm{~mL}$ hydrolysate) was adjusted to $\mathrm{pH} 7.0$ by adding concentrated $1.0 \mathrm{~mol} \mathrm{~L}^{-1} \mathrm{NaOH}$ (no. 10019762, Sinopharm Chemical Reagent Co., Ltd.) and cooling down to room temperature, then the suspension was washed with $100 \mathrm{~mL}$ of distilled water and centrifuged at $2000 \times g$ for $10 \mathrm{~min}$ (RJ-TDL50A, Wuxi Ruijiang Instruments Co. Ltd., China). The upper layer was discarded and the starch granules were washed three times with distilled water and freeze-dried on a Freezone $6 \mathrm{~L}$ instrument (Labconco Corporation., USA) at $12 \mathrm{~Pa}$ for $48 \mathrm{~h}$. Then, the treated starches were collected and stored in a desiccator at room temperature until physical properties analysis.

\section{Reducing sugar content and electrical conductivity}

The reducing sugar content of the hydrolysates were measured according to the 3,5-dinitrosalicylic acid (DNS) method ${ }^{22,23}$ with slight modifications. Distilled water $(1.0 \mathrm{~mL})$ and DNS solution $(2.0 \mathrm{~mL})$ were added successively to the supernatant fluid $(1.0$ $\mathrm{mL}$ of sample solution) and mixed thoroughly in a clean tube.

The tube was immediately placed into a boiling water bath for $5 \mathrm{~min}$ and cooled down quickly in an ice-water bath for $3 \mathrm{~min}$. Distilled water was then added to dilute the sample to $25.0 \mathrm{~mL}$ and mixed completely. The absorbance at $540 \mathrm{~nm}$ was detected on a V-1800 spectrophotometer (Mapada, Shanghai, China); $2.0 \mathrm{~mL}$ of a DNS solution and $23.0 \mathrm{~mL}$ of distilled water were mixed and used as controls. Electrical conductivity of the hydrolysates were determined via a conductivity meter (METTLER TOLEDO Instrument Shanghai Co., Ltd).

\section{Scanning electron microscopy (SEM)}

The microstructure of starch granules was observed using a Quanta-200 SEM device (FEI Company, Eindhoven, Netherlands). Samples were sprayed on an aluminum plate with double-sided adhesive and coated with a thin gold film $(10 \mathrm{~nm})$, then examined at an accelerating voltage of $5 \mathrm{kV}$ and magnified at $2400 \times$.

\section{X-ray diffractometry (XRD)}

Freeze-dried starch samples were packed tightly into a circular plastic cell, then their crystalline structures were analyzed on a D8 Advance XRD meter (Bruker AXS, Germany) with $\mathrm{Cu}-\mathrm{K} \alpha$ radiation $(\lambda=1.54056 \AA)$ at a target voltage of $40 \mathrm{kV}$, current of $40 \mathrm{~mA}$, scanning range $2 \theta=5-40^{\circ}$, and scanning rate of $4.0^{\circ}$ $\mathrm{min}^{-1}$. The relative crystallinity (RC) of starch was calculated as follows (eqn (8)):

$$
\mathrm{RC}=\frac{A_{\mathrm{a}}}{\left(A_{\mathrm{a}}+A_{\mathrm{c}}\right)}
$$

where $A_{\mathrm{c}}$ and $A_{\mathrm{a}}$ are the crystalline area and amorphous area on the XRD. ${ }^{24}$

\section{Differential scanning calorimetry (DSC)}

Native and treated maize starches were used for thermal analysis with a DSC meter (S II Nano Technology Inc., Seiko, Japan). Anhydrous starch ( $3 \mathrm{mg}$ ) was weighed directly in an aluminum pan, then $6 \mu \mathrm{L}$ of distilled water was added and the mixture was 
hermetically sealed. The samples were allowed to equilibrate at $4{ }^{\circ} \mathrm{C}$ for $12 \mathrm{~h}$, then heated at $10{ }^{\circ} \mathrm{C} \mathrm{min}{ }^{-1}$ from 20 to $90{ }^{\circ} \mathrm{C}$ in a nitrogen atmosphere (flow rate $=10 \mathrm{~mL} \mathrm{~min}^{-1}$ ), with an empty pan used as a reference. The onset, peak, and conclusion temperatures $\left(T_{\mathrm{o}}, T_{\mathrm{p}}, T_{\mathrm{c}}\right)$, as well as gelatinization enthalpy $(\Delta H)$, and gelatinization temperature range $(\Delta T)$ defined as $T_{\mathrm{c}}-$ $T_{\mathrm{o}}$ were determined accordingly. ${ }^{25,26}$

\section{Statistical analysis}

Statistical analysis was performed in ORIGIN 9.0 (OriginLab Inc., USA). Data were expressed as means of at least three measurements of one sample for each time period as-tested by one-way analysis of variance (ANOVA).

\section{Results and discussion}

\section{Preliminary experiment}

The hydrolysis of maize starches for reducing sugar using various methods is shown in Fig. 3. Reducing sugar contents during IEFAH treatment at $50{ }^{\circ} \mathrm{C}$ for $120 \mathrm{~h}$ with $0.15 \mathrm{~mol} \mathrm{~L}^{-1}$ hydrochloric acid improved by $175.05 \%, 132.43 \%$, and $89.62 \%$ respectively, compared to static immersion, $\mathrm{CHH}$, and $\mathrm{CFHH}(P<$ 0.05), suggesting that the massive orientational electromigration of charged ions under the IEF benefitted the separation of monosaccharose from amylopectin and amylose below the gelatinization temperature (Fig. 2b and c). Under electro-kinetics effects, the starch amorphous region can be effectively attacked by charged ions of $\mathrm{H}^{+}$and $\mathrm{Cl}^{-}$resulting in the acceleration of chain scission and increase in reducing sugar content. There are differences among the conductivity of starch hydrolysates when subjected to the treatments (Table 1). The conductivity of IEFAH was higher than those of static immersion, $\mathrm{CHH}$, and $\mathrm{CFHH}$. The enhancement of electric conduction in the medium is conducive to energy utilization and conversion via the magnetoelectric coupling effect, resulting in the successive acceleration of acid hydrolysis. ${ }^{27}$ Results suggest that more hydrolytic fragmentcarrying charges were produced during the IEFAH. In future, molecular weight distributions in the hydrolysates after electrofluid hydrolysis merits further study.

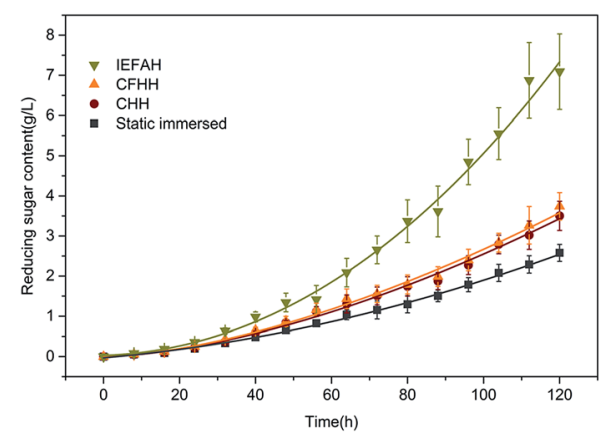

Fig. 3 Time course of reducing sugar content as maize starch is subjected to different hydrolysis methods at $50{ }^{\circ} \mathrm{C}, \mathrm{pH}$ of 1.5 , and the solid-liquid ratio of $8 \%(\mathrm{w} / \mathrm{v})$ for $120 \mathrm{~h}(\mathrm{CFHH}$ and IEFAH in 1-series system).
Though high-intensity pulsed electric field treatment is beneficial for modifying starch in regards to shorter reaction time, it is disadvantageous in industrial-level processing due to heavy metal contamination and the necessity for complex and bulky equipment. ${ }^{28}$ The application of other physical fields (e.g., sound fields, electromagnetic fields) also benefits starch hydrolysis. Wheat starch hydrolysis by $\mathrm{pH} 1.85$ acidic solution plus microwave radiation produces starch hydrolysates containing $94.81 \%$ total sugars, $88.69 \%$ reducing sugars, and $83.56 \%$ glucose ${ }^{29}$ but the difficulty inherent to controlling the microwave reaction temperature and resulting rapid heating of the starch suspension are problematic. ${ }^{30}$ The acidic hydrolysis of waxy maize starch coupled with ultrasonic treatment in a $3.16 \mathrm{~mol} \mathrm{~L}^{-1}$ sulfuric acid solution at $40{ }^{\circ} \mathrm{C}$ for one week can effectively promote the amount of nanocrystalline starch from $20 \%$ to $70 \%$. $^{31}$ The acceleration of random $\mathrm{H}^{+}$movement is the primary mechanism for enhancing hydrolysis in the above techniques. These phenomena also suggest, however, that IEF is conducive to the control under mild conditions in long-term treatment.

\section{Electrofluid transformation of starches into reducing sugar}

Effect of temperature. The reducing sugar content after IEFAH treatment at various temperatures is shown in Fig. 4. Clearly, the acid hydrolysis of maize starch was significantly affected by IEF at lower temperatures, especially 30 and $40{ }^{\circ} \mathrm{C}$; reducing sugar content at processing time of $60 \mathrm{~h}$ increased by $59.88 \%$ at $30{ }^{\circ} \mathrm{C}$ and by $118.99 \%$ at $40{ }^{\circ} \mathrm{C}$ compared to $\mathrm{CFHH}$. Reducing sugar content increased by only $15.12 \%$ at $50{ }^{\circ} \mathrm{C}$ after $60 \mathrm{~h}$, however. The thermal effects of acidic starch hydrolysis have been extensively reported to date. For example, the changes in modified waxy corn starch after treatment with $0.15 \mathrm{~mol} \mathrm{~L}{ }^{-1} \mathrm{HCl}$ at 20 and $50{ }^{\circ} \mathrm{C}$ were investigated; ${ }^{32}$ the viscosity profile (RVA) showed that all parameters reduced to a greater extent after hydrolysis at $50{ }^{\circ} \mathrm{C}$ than at $20{ }^{\circ} \mathrm{C}$. The results of our study suggest that the electrical effect dominates the thermal effect (Brown motion) under mild conditions on maize starch, but that the intensive motion of charged ions during hydrolysis at higher temperature can disturb the orientated electromigration of charged ions. A similar phenomenon was observed by Mozumder. ${ }^{33}$ It is possible to use electric fields to improve mass transport at appropriate thermal energy. ${ }^{34,35}$ In effect, IEF can indeed enhance the sugar yield during maize starch acid hydrolysis at appropriate temperature.

Effect of excitation voltage. Reducing sugar contents, as shown in Fig. 5a, increased as excitation voltage increased with significant differences between treatments at $0 \mathrm{~V}$ and $150 \mathrm{~V}$. A core with higher magnetic saturation, to this effect, would enhance the excitation voltage in practice. The increase in electric field strength can enhance the ionic conduction. ${ }^{36,37}$ and thereby accelerate mass transport and collision between chargecarrying solutes and starch granules. The elevated excitation voltage also improved the input power of the system and thereby increased the effects of the field and reducing sugar content. 
Table 1 Electrical conductivity of the starch hydrolysates during different hydrolysis methods at $50{ }^{\circ} \mathrm{C}$, $\mathrm{pH}$ of 1.5 , and the solid-liquid ratio of $8 \%$ $(\mathrm{w} / \mathrm{v})$ for $120 \mathrm{~h}(\mathrm{CFHH} \text { and IEFAH in 1-series system })^{a}$

\begin{tabular}{lllll}
\hline Time $(\mathrm{h})$ & Static immersed $\left(\mathrm{mS} \mathrm{cm}^{-1}\right)$ & CHH $\left(\mathrm{ms} \mathrm{cm}^{-1}\right)$ & CFHH $\left(\mathrm{mS} \mathrm{cm}^{-1}\right)$ & IEFAH $\left(\mathrm{mS} \mathrm{cm}^{-1}\right)$ \\
\hline 0 & $104.67 \pm 0.36^{\mathrm{a}}$ & $104.71 \pm 0.58^{\mathrm{a}}$ & $106.72 \pm 0.75^{\mathrm{b}}$ & $106.32 \pm 0.69^{\mathrm{b}}$ \\
12 & $103.91 \pm 1.02^{\mathrm{a}}$ & $104.93 \pm 0.98^{\mathrm{a}}$ & $108.98 \pm 0.73^{\mathrm{b}}$ & $109.68 \pm 0.56^{\mathrm{b}}$ \\
24 & $103.98 \pm 0.89^{\mathrm{a}}$ & $103.82 \pm 0.77^{\mathrm{a}}$ & $111.09 \pm 0.56^{\mathrm{b}}$ & $114.17 \pm 0.32^{\mathrm{c}}$ \\
36 & $103.59 \pm 1.01^{\mathrm{a}}$ & $104.60 \pm 0.62^{\mathrm{a}}$ & $115.15 \pm 0.45^{\mathrm{b}}$ & $119.03 \pm 0.47^{\mathrm{c}}$ \\
48 & $103.52 \pm 0.72^{\mathrm{a}}$ & $106.01 \pm 0.59^{\mathrm{b}}$ & $119.23 \pm 0.72^{\mathrm{c}}$ & $122.11 \pm 0.33^{\mathrm{d}}$ \\
60 & $104.85 \pm 0.88^{\mathrm{a}}$ & $106.85 \pm 1.01^{\mathrm{b}}$ & $122.11 \pm 0.58^{\mathrm{c}}$ & $124.39 \pm 0.92^{\mathrm{d}}$ \\
72 & $104.29 \pm 0.57^{\mathrm{a}}$ & $106.06 \pm 0.72^{\mathrm{b}}$ & $124.21 \pm 0.67^{\mathrm{c}}$ & $129.98 \pm 0.55^{\mathrm{d}}$ \\
84 & $104.20 \pm 0.98^{\mathrm{a}}$ & $108.04 \pm 0.44^{\mathrm{b}}$ & $128.52 \pm 1.03^{\mathrm{c}}$ & $133.60 \pm 0.78^{\mathrm{d}}$ \\
96 & $105.83 \pm 1.10^{\mathrm{a}}$ & $109.29 \pm 0.96^{\mathrm{b}}$ & $130.71 \pm 0.67^{\mathrm{c}}$ & $136.22 \pm 0.32^{\mathrm{d}}$ \\
108 & $106.27 \pm 0.55^{\mathrm{a}}$ & $111.26 \pm 0.88^{\mathrm{b}}$ & $134.71 \pm 1.10^{\mathrm{c}}$ & $140.16 \pm 1.22^{\mathrm{c}}$
\end{tabular}

${ }^{a}$ Average of triplicate measurements, $n=3, \pm$ means standard deviation. Note: values in the same row with different letters are significantly different $(P<0.05)$.

Effects of reactor series. The system is conducive to scaling up for high throughput processing and is also reconfigurable with series-parallel connection related to their equivalent circuit. In this study, the effect of increased reactors in series connection on hydrolysis was investigated. The results showed
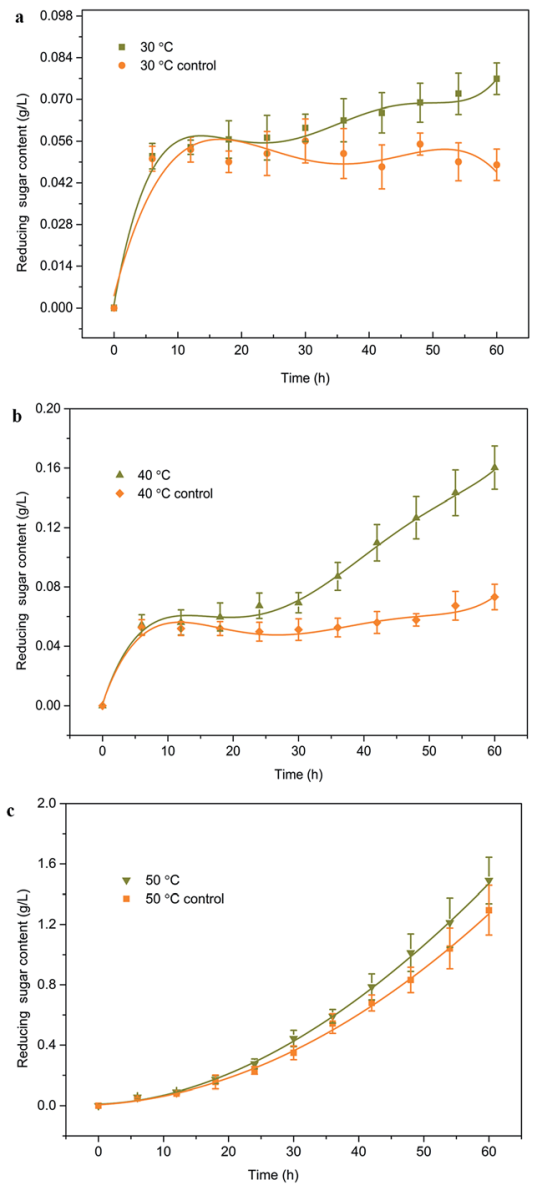

Fig. 4 Time course of reducing sugar content as maize starch is subjected to IFEAH in 1-series system at different temperatures, $100 \mathrm{~V}$, $400 \mathrm{~Hz}, \mathrm{pH}$ of 1.5 , and solid-liquid ratio of $8 \%(\mathrm{w} / \mathrm{v})$ for $60 \mathrm{~h}$ : (a) $30^{\circ} \mathrm{C}$; (b) $40{ }^{\circ} \mathrm{C}$; (c) $50{ }^{\circ} \mathrm{C}$. that differences in equivalent parameters including $Z_{\text {total }}$ and $E_{\text {total }}$ significantly affect the reducing sugar content (Fig. 5b). For example, the reducing sugar content from the 4-series system compared to the 1-, 2-, and 3-series systems improved by $194.27 \%, 76.71 \%$, and $29.87 \%$, respectively, where $E_{\text {total }}$ in the series connection reaction system increased linearly during the process. The increase in the electric field strength increased the motion displacement of charge-carrying solutes, improving its effects on starch hydrolysis. The increase in reactor series also improved the processing capacity. These observations suggest that reactors in other series-parallel connection modes could also affect the yield due to the changes in $Z_{\text {total }}$ and $E_{\text {total }}$ of the system.

The acid hydrolysis of starch under high-intensify pulsed electric field techniques is restricted by electrochemical reaction owing to metal electrode and rigorous energy discharge. Rectangle waves are typically utilized for pulsed electric field treatment, ${ }^{21}$ but the current technique facilitates the mutual conversion between electric energy and magnetic energy via sine waves without necessitating a metal electrode. In addition, enzyme inactivation by applied high-voltage electric fields is generally considered to be under mild conditions. ${ }^{38}$ The acceleration or deceleration of enzymatic hydrolysis of carbohydrate polymers under electrical effect (moderate electric field at
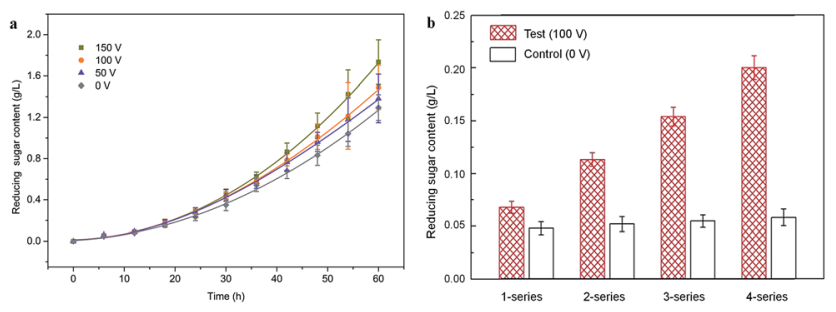

Fig. 5 Effects of excitation voltage and reactor series: (a) time course of reducing sugar content as maize starch is subjected to IFEAH in 1series system at different excitation voltages, $400 \mathrm{~Hz}, \mathrm{pH}$ of $1.5,50{ }^{\circ} \mathrm{C}$, and solid-liquid ratio of $8 \%(\mathrm{w} / \mathrm{v})$ for $60 \mathrm{~h}$; (b) effect of reactor series on reducing sugar content as maize starch is subjected to IFEAH at $100 \mathrm{~V}$, $400 \mathrm{~Hz}, \mathrm{pH}$ of $1.5,40{ }^{\circ} \mathrm{C}$, and solid-liquid ratio of $8 \%(\mathrm{w} / \mathrm{v})$ for $24 \mathrm{~h}$. 
a frequency of $\left.50-60 \mathrm{~Hz},<15 \mathrm{~V} \mathrm{~cm}^{-1}\right)$ and thermal effect $\left(50{ }^{\circ} \mathrm{C}\right)$ has also been reported. ${ }^{14}$

\section{Physical analysis of modified starch}

SEM. The effect of acid hydrolysis on starch granule morphology is related to the sources of starch and the degree of acid hydrolysis. SEM graphs of the native and treated starches are shown in Fig. 6. The native maize starch granules were smooth (Fig. 6a) after acid hydrolysis (0 V), though several were damaged (Fig. 6b). With the application of IEF, some damaged granules were also observed (Fig. 6c-e). The increase in surface roughness is related to a gradual extension of hydrolysis time. Though most of the granules maintained their original (polygonal) shape, when the starch was dispersed in a $3.16 \mathrm{~mol} \mathrm{~L}^{-1}$ sulphuric acid solution after stirring and was held at $35{ }^{\circ} \mathrm{C}$ for 15 days, a portion of the starch granule presented slight exoerosion on the surface after the first day of hydrolysis that gradually increased by the third day. After lengthier hydrolysis duration (over five days), deformation on the surface of the acidtreated granules was observed. ${ }^{39}$ Błaszczak et al. ${ }^{40}$ suggested that the outer part of starch granules have a very dense layer resistant to electricity under mild conditions. The electroconductive medium contains an abundance of free ions. This increased
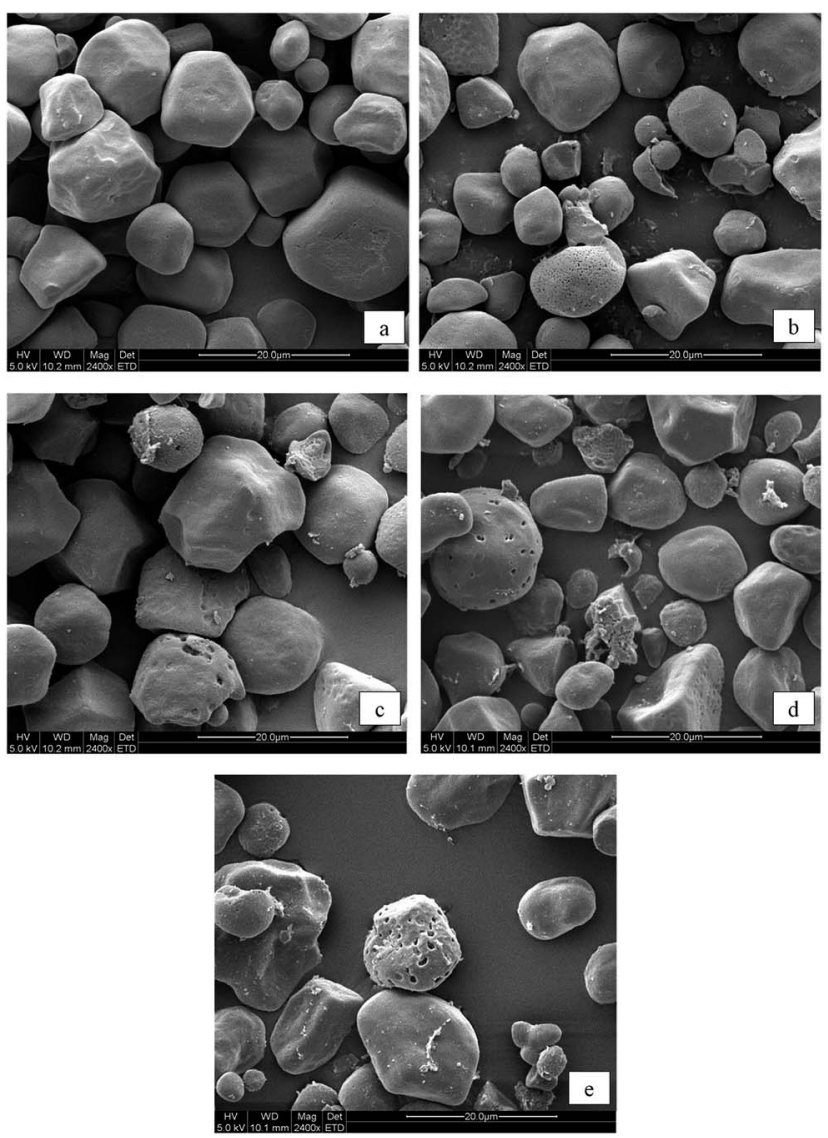

Fig. 6 Microscopic observations of native and treated starch in 1 series system at different excitation voltages, $400 \mathrm{~Hz}, 50{ }^{\circ} \mathrm{C}, \mathrm{pH}$ of 1.5 , and the solid-liquid ratio of $8 \%(w / v)$ for $60 \mathrm{~h}$ : (a) native starch; (b) $0 \mathrm{~V}$; (c) $50 \mathrm{~V}$; (d) $100 \mathrm{~V}$; (e) $150 \mathrm{~V}$. electric field strength accelerated the periodic reciprocal motion of charge-carrying solutes, and promoted the probability of collision among the solutes and starch granules. A certain degree of damage on the granule morphology may be caused by the field. However, no significant difference between the granule morphology and excitation voltage were observed. Compared to high-intensify pulsed electric field processing, the efficiency of electrical energy induced by the magnetic energy applied in the process was low due to the low magnetic saturation and flux density in current study. Thus, more significant damage on the starch granules may be induced by intensified IEF based on the resulting high magnetomotive force. ${ }^{27}$

XRD. The crystalline structures of starch hydrolysates influenced by different excitation voltages are shown in Fig. 7a. The native maize starch sample showed the typical A-type pattern of cereal starch with major peaks at $2 \theta=15,17,18$, and $23^{\circ}$ (ref. 41 and 42 ) with a relative crystallinity of $26.9 \%$. CFHH and IEFAH did not alter the structural pattern of maize starch but showed different impacts on its crystallinity. But, CFHH caused a slight increase in crystallinity, which was coincidence with the agreements that acidic hydrolysis likely intensified the crystallinity by first splitting the starch chains in the amorphous regions. ${ }^{43}$ However, the diffraction peaks after IEF treatments at various intensities were less intense, indicating that higher excitation voltage caused lower peak intensities $26.73 \%(50 \mathrm{~V})$, $25.82 \%(100 \mathrm{~V})$, and $24.94 \%(150 \mathrm{~V})$.

As previously reported, any decrease in relative crystallinity by pulsed electric fields is attributable to amylopectin crystallite disruption. Pulsed electric field treatment can destroy the crystalline region of starches by supplying large amounts of energy to the reaction in the short-term between starch molecule chains and water molecules by forming hydrogen bonds. ${ }^{44}$
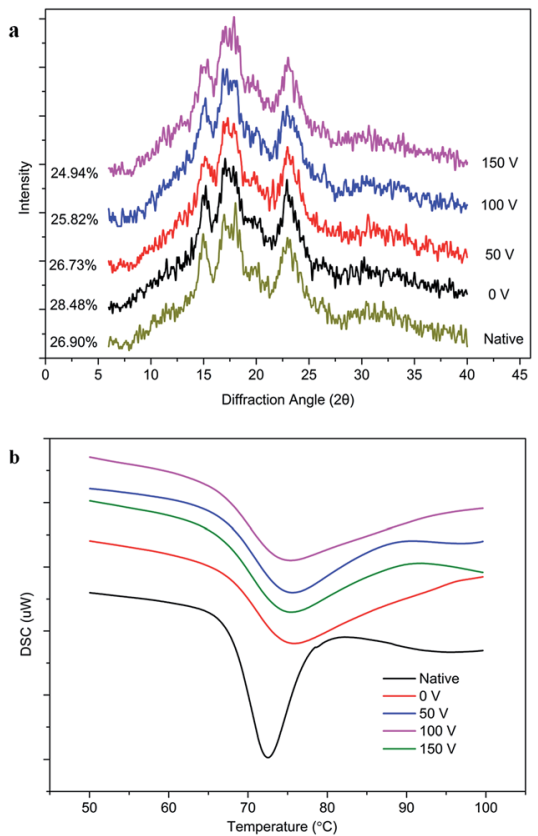

Fig. 7 Physical analysis of native and treated starch in 1-series system at different excitation voltages, $400 \mathrm{~Hz}, 50{ }^{\circ} \mathrm{C}, \mathrm{pH}$ of 1.5 , and the solidliquid ratio of $8 \%(w / v)$ for $60 \mathrm{~h}$ : (a) XRD; (b) DSC. 
Table 2 DSC analysis of gelatinization properties of native and treated starch at different excitation voltages, $400 \mathrm{~Hz}, 50{ }^{\circ} \mathrm{C}, \mathrm{pH}$ of 1.5, and the solid-liquid ratio of $8 \%(\mathrm{w} / \mathrm{v})$ in 1 -series system for $60 \mathrm{~h}^{a}$

\begin{tabular}{llllr}
\hline Sample & $T_{\mathrm{o}}\left({ }^{\circ} \mathrm{C}\right)$ & $T_{\mathrm{p}}\left({ }^{\circ} \mathrm{C}\right)$ & $T_{\mathrm{c}}\left({ }^{\circ} \mathrm{C}\right)$ & $\Delta T\left({ }^{\circ} \mathrm{C}\right)$ \\
\hline Native & $68.52 \pm 0.50^{\mathrm{a}}$ & $72.30 \pm 0.17^{\mathrm{a}}$ & $76.31 \pm 0.07^{\mathrm{a}}$ & $7.80 \pm 0.43^{\mathrm{a}}$ \\
$0 \mathrm{~V}$ & $68.11 \pm 0.84^{\mathrm{a}}$ & $75.71 \pm 0.04^{\mathrm{b}}$ & $86.04 \pm 0.31^{\mathrm{b}}$ & $17.93 \pm 0.53^{\mathrm{b}}$ \\
$50 \mathrm{~V}$ & $67.99 \pm 0.33^{\mathrm{a}}$ & $75.65 \pm 0.22^{\mathrm{b}}$ & $85.98 \pm 0.77^{\mathrm{b}}$ & $17.99 \pm 0.56^{\mathrm{a}}$ \\
$100 \mathrm{~V}$ & $67.83 \pm 0.59^{\mathrm{a}}$ & $75.55 \pm 0.22^{\mathrm{b}}$ & $85.24 \pm 0.80^{\mathrm{b}}$ & $17.31 \pm 0.14^{\mathrm{a}}$ \\
$150 \mathrm{~V}$ & $67.69 \pm 0.25^{\mathrm{a}}$ & $75.51 \pm 0.17^{\mathrm{b}}$ & $84.72 \pm 0.80^{\mathrm{b}}$ & $14.85 \pm 0.39^{\mathrm{a}}$ \\
& & & $17.03 \pm 0.55^{\mathrm{a}}$ & $14.57 \pm 0.44^{\mathrm{a}}$
\end{tabular}

${ }^{a} T_{\mathrm{o}}$, onset temperature; $T_{\mathrm{p}}$, peak temperature; $T_{\mathrm{c}}$, conclusion temperature; $\Delta T$, temperature range for gelatinization; and $\Delta H$, enthalpy of gelatinization. Average of triplicate measurements, $n=3, \pm$ means standard deviation. Values in the same column with different letters are significantly different $(P<0.05)$.

The decrease in relative crystallinity we observed in this study suggests that the IEF disrupted the amorphous region of maize starch granules as well as the crystalline area. Acidic environments accelerated the hydrolysis of maize starch granules successively under the IEF owing to the enhanced ionic conductivity (Table 1). The enhancement of environmental conductivity is conducive to the hydrolysis efficiency under the field due to the decrease in medium impedance and improvement to energy utilization. ${ }^{45}$ Acid solutions first hydrolyze the non-crystalline area to truncate the starch chains and then attack the crystalline regions. ${ }^{46}$ Thus, the relative crystallinity only slightly decreased in IEF-treated samples as electric field strength increased.

DSC. The thermal behaviors of starch after various treatments are shown in Fig. 7b. The phase transition temperature (onset, $T_{\mathrm{o}}$; peak, $T_{\mathrm{p}}$; and conclusion, $T_{\mathrm{c}}$ ), gelatinization temperature range $(\Delta T)$, and gelatinization enthalpy $(\Delta H)$ are listed in Table 2. IEFAH shifted the onset gelatinization temperature to lower temperatures but increased the peak and conclusion temperatures. As a result, the transition temperature range was broadened by $10{ }^{\circ} \mathrm{C}$ after IEFAH. This phenomenon was caused by the heterogeneity of the crystallites formed from varying entities, such as crystalline amylopectin side chains, retrograded amylose, and amyloselipid complexes, which were in accordance with results reported in a previous study. ${ }^{31}$ It is important to note that the phase transition temperatures showed little change as excitation voltage increased from 50 to $150 \mathrm{~V}$, that the tested voltages displayed few differing effects on gelatinization properties of maize starch. Furthermore, compared to the native starch, the gelatinization enthalpy of IEF-treated starch was increased, but was slightly reduced as the excitation voltage strengthened, which can be ascribed to the variation of crystallinity (Fig. 7a).

\section{Conclusions}

In this study, a continuous-flow mixture of maize starch and acidic solvent was subjected to IEF and assessed. As opposed to enzymatic starch hydrolysis in a batch reactor under mild conditions, hydrolysis was intensified due to enhanced ionic conduction caused by the magnetoelectric coupling effect. The acid hydrolysis of maize starch was significantly affected by IEF at lower temperatures, especially 30 and $40{ }^{\circ} \mathrm{C}$. Reducing sugar content increased as excitation voltage and reactor series increased due to increase in $E_{\text {total }}$ and $P_{\text {in }}$. XRD results showed a slight decrease in relative crystallinity in the IEF-treated starches compared to the controls. The gelatinization temperature also slightly decreased as excitation voltage increased. In summary, electrofluidic hydrolysis is an efficient and ecofriendly technique for producing acid-modified starch and syrup.

\section{Abbreviations}

IEFAH

$\mathrm{CFHH}$

$\mathrm{CHH}$

IEF

FSS

$\mathrm{RC}$

$E_{\text {total }}$

$\mathrm{AC}$

DC

\author{
Induced-electric-field-assisted hydrolysis \\ Continuous-flow heating hydrolysis \\ Conventional heating hydrolysis \\ Induced electric field \\ Flowing sample solution \\ Relative crystallinity \\ Total induced voltage \\ Alternative current \\ Direct current
}

\section{Acknowledgements}

This study was financially supported by the Prospective Joint Research Project of Jiangsu Province (No. BY2016022-06), the National Natural Science Foundation of China (No. 31501523) and the Special Fund for Agro-scientific Research in the Public Interest (No. 201303070-02).

\section{References}

1 C. Hernández-Jaimes, R. G. Utrilla-Coello, H. Carrillo-Navas, E. García-Márquez, M. Meraz, L. A. Bello-Pérez, E. J. VernonCarter and J. Alvarez-Ramirez, Starch, 2014, 66, 636-644.

2 M. Ulbrich, V. Lampl and E. Flöter, Starch, 2016, 68, 1-15.

3 F. Li, L. Liu, Y. An, W. He, N. J. Themelis and G. Li, J. Cleaner Prod., 2016, 112, 1049-1054.

4 V. Singh and S. Z. Ali, Carbohydr. Polym., 2000, 41, 191-195.

5 Y. N. Shariffa, A. A. Karim, A. Fazilah and I. S. M. Zaidul, Food Hydrocolloids, 2009, 23, 434-440. 
6 D. P. Bayrock and W. M. Ingledew, J. Ind. Microbiol. Biotechnol., 2001, 27, 87-93.

7 R. Manelius, K. Nurmi and E. Bertoft, Cereal Chem., 2000, 77, 345-353.

8 S. Karagöz, T. Bhaskar, A. Muto, Y. Sakata and M. A. Uddin, Energy Fuels, 2004, 18, 234-241.

9 M. Agamori and T. Funazukuri, J. Chem. Technol. Biotechnol., 2004, 79, 229-233.

10 S. Cui, S. Zhang, S. Ge, L. Xiong and Q. Sun, Ind. Crops Prod., 2016, 83, 346-352.

11 J. Ahmed, L. Thomas, A. Taher and A. Joseph, Carbohydr. Polym., 2016, 152, 639-647.

12 J. Ni, H. Na, Z. She, J. Wang, W. Xue and J. Zhu, Bioresour. Technol., 2014, 167, 69-73.

13 Z. Han, X. A. Zeng, N. Fu, S. J. Yu, X. D. Chen and J. F. Kennedy, Carbohydr. Polym., 2012, 89, 1012-1017.

14 E. K. Durham, Moderate electric field treatment for saccharification of cellulosic materials, The Ohio State University, 2015.

15 J. Morren, B. Roodenburg and S. W. de Haan, Innovative Food Sci. Emerging Technol., 2003, 4, 285-295.

16 R. W. Pryor, Proceedings of the thirteenth COMSOL Conference, Boston, 2013.

17 F. W. Sears, Am. J. Phys., 1963, 31, 439-443.

18 L. M. Jesus, R. S. Silva, R. Raj and J.-C. M'Peko, RSC Adv., 2016, 6, 107208-107213.

19 H. R. Hartman and K. F. Jensen, Lab Chip, 2009, 9, 24952507.

20 K. Geyer, T. Gustafsson and P. H. Seeberger, Synlett, 2009, 5, 2382-2391.

21 S. V. Kulkarni and S. A. Khaparde, Transformer Engineering: design, technology, and diagnostics, CRC Press, Boca Raton, 2013.

22 R. Hu, L. Lin, T. Liu, P. Ouyang, B. He and S. Liu, J. Biobased Mater. Bioenergy, 2008, 2, 156-161.

23 Y. Liu, P. Luo, Q. Xu, E. Wang and J. Yin, Cellul. Chem. Technol., 2014, 48, 89-95.

24 S. Nara and T. Komiya, Starch, 1983, 35, 407-410.

25 M. Kaur, N. Singh, K. S. Sandhu and H. S. Guraya, Food Chem., 2004, 85, 131-140.
26 K. S. Sandhu and N. Singh, Food Chem., 2007, 101, 14991507.

27 N. Yang, Y. Jin, D. Li, Z. Jin and X. Xu, Chem. Eng. J., 2017, 313, 599-609.

28 H. Jing, R. Chen, X. A. Zeng and H. Zhong, Food Chem., 2016, 192, 15-24.

29 A. R. Khan, R. J. Robinson and J. A. Johnson, J. Food Sci., 1980, 45, 1449.

30 K. Li, L. Xia, J. Li, J. Pang, G. Cao and Z. Xi, Carbohydr. Res., 2001, 331, 9-12.

31 H. Y. Kim, J. A. Han, D. K. Kweon, J. D. Park and S. T. Lim, Carbohydr. Polym., 2013, 93, 582-588.

32 C. S. de Oliveira, M. M. P. Andrade, T. A. D. Colman, F. J. O. G. da Costa and E. Schnitzler, J. Therm. Anal. Calorim., 2014, 115, 13-18.

33 A. Mozumder, J. Chem. Phys., 1974, 60, 4300-4304.

34 A. Amadei and P. Marracino, RSC Adv., 2015, 5, 96551-96561.

35 R. Basori and A. Raychaudhuri, RSC Adv., 2015, 5, 8649786504.

36 C. Kusnadi and S. K. Sastry, J. Food Eng., 2012, 110, 329-336.

37 Y. Jin, N. Yang, Q. Ma, F. Wu, X. Xu and Q. Tong, Food Bioprocess Technol., 2015, 8, 749-757.

38 P. Sharma, I. Oey, P. Bremer and D. W. Everett, Int. Dairy J., 2014, 39, 146-156.

39 R. Utrilla-Coello, C. Hernández-Jaimes, H. Carrillo-Navas, F. González, E. Rodríguez, L. A. Bello-Perez, E. VernonCarter and J. Alvarez-Ramirez, Carbohydr. Polym., 2014, 103, 596-602.

40 W. Błaszczak, S. Valverde and J. Fornal, Carbohydr. Polym., 2005, 59, 377-383.

41 S. H. Mun and M. Shin, Food Chem., 2006, 96, 115-121.

42 J. Hasjim and J. L. Jane, J. Food Sci., 2009, 74, C556-C562.

43 S. Wang and L. Copeland, Crit. Rev. Food Sci. Nutr., 2015, 55, 1081-1097.

44 F. Zeng, Q. Gao, Z. Han, X. Zeng and S. Yu, Food Chem., 2016, 194, 1313-1319.

45 H. Jaeger, A. Roth, S. Toepfl, T. Holzhauser, K. H. Engel, D. Knorr, F. Rudi, V. N. Bandickg, S. Kullingh and P. Steinberg, Trends Food Sci. Technol., 2016, 55, 84-97.

46 R. Hoover, Food Rev. Int., 2000, 16, 369-392. 